\title{
Early understandings of simple food chains: A learning progression for the preschool years
}

\begin{abstract}
Aspects of preschoolers' ecological understandings were explored in a cross-age, quantitative study that utilised a sample of seventy-five 3-5 year-old children. Specifically, their concepts of feeding relationships were determined by presenting physical models of three-step food chains during structured interviews. A majority of children, particularly 5 year-olds, were capable of grasping concepts inherent in food chain topics that are scheduled to appear later in their schooling. In part, age differences in children's reasoning can be accounted for by attentional theory based on evolutionary predator avoidance adaptations, which tended to become significant at 5 years. Data suggest that these aspects of preschool ecological education could be increased in sophistication, thus accelerating children's understandings about the environment beyond what is currently the case.
\end{abstract}

Key words: preschool science; ecology education; food chains; learning progression.

\section{Introduction}

Calls for an early ecological education have been driven by a perception that young children in developed countries spend an increasing amount of time indoors, failing to interact with the natural world and not constructing appropriate biological concepts or developing positive attitudes towards the local environment (Smith, 2001; Taşkın \& Şahin, 2008). Slarp (2014) discusses how quality interventions in the early years prior to school are effective in shaping long-lasting cognitive and emotional aspects of children's development, linking some adults' 
lack of concern about the environment with a past deficiency of necessary experience in their early childhood.

Different wild species depend upon each other for survival; for instance an oak tree provides essential shelter for a sparrow, whilst also acting as a food source for an oak moth caterpillar. An understanding of such interdependences is a cornerstone of biology education, enabling appreciation of more complex ecological ideas (author, 2016; Manzanal, Barreiro, \& Jiménez, 1999). Particularly, insight into how organisms rely on each other for nourishment acts as a precursor for learning about such diverse biological topics as food webs, succession of species and natural selection. As well as being necessary for scientific competence, comprehending how feeding relationships operate in the wild is important for wider ecological literacy reasons (White, 2000). Environmental reports of events in the media such as the extinction of species due to deforestation, global warming-related coral reef depletion, marine oil spills, the re-introduction of wild wolves and beavers into the UK countryside, and horsemeat being discovered in 'beef' products, require at least a basic understanding of how food chains work. The topic of evolution has been recently introduced to the primary science curriculum in England (Department for Education, 2013), bringing an additional spotlight to fall on an appreciation of how feeding relationships and predator/prey roles are important in natural selection processes.

Young children's natural egocentrism and anthropocentrism act as barriers to a proper understanding of a number of ecological concepts (Öztürk, 2010). Nevertheless, for children to be able to comprehend environmental scenarios presented both in the nursery and in later life, an effective early ecological education is desirable. Erroneous ideas about food chains have been uncovered in high frequencies in samples of school children, often continuing 
unchanged into adulthood (e.g. Sander, Jelemenska, \& Kattmann, 2006). The current study represents an attempt to characterise for the first time preschool children's food chain concepts in a systematic way in order to look for early origins of these misconceptions, and so illuminate how people of all ages might apply their reasoning to this key area of biology education.

\section{Previous research on children's concepts of food chains}

This section will briefly review the considerable amount of research that has explored the concepts held by young learners pertaining to food chains and food webs. There is however, a dearth of work at preschool level (birth to 5 years). Consequently, studies are included that have sampled primary children (5-11 years), with children's ideas presented as potential examples of what preschoolers may similarly be thinking.

Children of primary age are able to grasp simple aspects of feeding relationship pairs. For instance, they understand that one animal can be the predator of another, or less commonly, an animal can utilise a plant as a food source (e.g. Arkwright, 2014; Gallegos, Jerezano, \& Flores, 1994; Strommen, 1995). Unless prompted however, children rarely consider relationships beyond these simple pairings, discuss three-step (or higher) food chains, or how interdependent populations might affect each other (Leach, Driver, Scott, \& Wood-Robinson, 1992; Slarp, 2014; Shepardson, 2002). Some younger primary children find it difficult to conceptualise interdependence per se, preferring to think of plants and animals as isolated individuals instead of as populations competing for survival over scarce resources. Some imagine that different species collaborate, talking freely and helping each other when in need (Leach et al., 1992). Anthropocentric reasoning is common with these younger children who 
believe that wild animals cannot exist without people to feed and look after them (Almeida, Vasconcelos, Strecht-Ribeiro, \& Torres, 2013; Demetriou, Korfiatis, \& Constantinou, 2009; Leach et al., 1992). Similarly, Einsen and Stavy (1992) describe how plants are thought by some secondary-aged students to be dependent on humans, instead of humans relying on plants for food, oxygen, etc. On the other hand, some of Jiménez-Tejada, Sánchez-Monsalve, and González-García's (2013) 11-12 year-olds thought that humans could not be part of an ecosystem.

Although not included within the English primary curriculum, children are typically taught that food chains can be used to explore how a change in the population numbers of one member affects other members of the chain. However, once children are at the stage of working with food chains in this more dynamic way common misconceptions emerge, with many relating to not considering the food chain as a whole entity, and instead focusing exclusively on a small part. Fundamentally, some children see a food chain as a static equation that merely has to be read and memorised, and not as a dynamic system that is liable to change (Hmelo-Silver, Marathe, \& Liu, 2007; Hogan, 2000). They do not yet understand that changes in one section can effect changes in other parts of the chain (Demetriou et al., 2009; Gotwalls \& Songer, 2010). Even children who have grasped dynamism frequently see a food chain as a semi-static entity, where only pairs of organisms adjacent in the chain can affect each other (Arkwright, 2014; Gotwalls \& Songer, 2010; Hogan, 2000; Leach et al., 1992). Alternately, older primary children extend their reasoning beyond the food chain and conclude that animals can easily change their diets if there is a shortage of a stated food source and eat foods not present in the chain (Leach et al., 1992; Smith, 2004). Munson (1994) found similar extra-chain reasoning when secondary-aged students said that removing one species from a chain would not matter because its place would be taken by a different 
species external to the chain. Such erroneous concepts of infinite resources in an ecosystem interfere with a correct view of environmental sustainability. It also has been shown that upper secondary-aged students are willing to skip trophic levels, ignoring the adjacency rule and have, for instance, a predator able to eat a plant (Griffiths \& Grant, 1985).

When considering the effects of changing populations children tend to be able to more easily comprehend changes up the trophic levels, than down - i.e. in the direction producer (plant) $\rightarrow$ primary consumer (herbivore) $\rightarrow$ secondary consumer (carnivore) (Demetriou et al., 2009; Gotwalls \& Songer, 2010; Leach et al., 1992). For example, they can appreciate that if there is a fall in a population of rabbits due to disease then this would mean foxes would starve and begin to die. Researchers have accounted for this trend by stating a reduction in a prey population causing predator starvation is easier to understand than proliferation of prey as a result of predator decline. These misconceptions can be linked to semi-static views, e.g. the death of a top predator has no effect on other organisms lower in the chain (Leach et al., 1992), or that a population at a lower trophic level cannot be affected by changes originating from higher trophic levels (Arkwright, 2014). That said, data collected by Hogan (2000) found an opposite trend where changes down the trophic levels were more easily understood, specifically that a prey population would thrive if there were a lack of predators. Children sometimes exhibit 'plant blindness', concluding that changes in plant populations are inconsequential to the rest of the food chain (Hogan, 2000; Hogan \& Fisherkeller, 1996; Leach et al., 1992).

As stated, there has been a near absence of food chain findings at the preschool level, although two rare studies are relevant to the current research. Ergazaki and Andriotou (2010) found that 4-5 year-olds could recognise feeding relationships pairs when discussing the 
inhabitants of a forest. Around two-thirds of children knew that elimination of a prey species as a consequence of human hunting would lead to the possibility of predator death, with nearly a quarter citing a lack of food as the reason (this effect goes up the trophic levels). However, other children used extra-chain reasoning and rationalised that predators would survive the eradication of their prey because they could migrate to another place to locate food, or just find a different prey species. Over $90 \%$ of children did not accept that destruction of all the plants due to a fire would affect animals in the forest, a common justification being that animals would be fine because they will migrate. The authors mention no progressions in thinking with age.

Katsiavou, Liopeta, and Zogza (2000) sampled 4-6 year-old children who were able to correctly name species in food webs, though half could not see any feeding relationships unless they were prompted. Children were unable to recognise the dynamic nature of food webs, specifically that changes in the population of one species could affect other species in the web. Plant blindness was widespread, with children thinking that if the plant population decreased then this would have no effect on animals in the web. Since the study used food webs and not chains as a diagnostic tool it is a challenge to use these data to form clear inferences about children's understandings of specific pairs of linked organisms in the web. This is because unlike food chains, changes in a population can affect other populations by means of multiple pathways in the web. Similarly, Suzuki, Yamaguchi, and Hokayem (2015) found that primary-aged children had great difficulties when assessing individual feeding relationships within a food web. Katsiavou et al. used a small sample so no meaningful agerelated conceptual progressions can be deduced from the data.

\section{Theoretical framework: Attentional biases and cognitive preferences}


It has long been determined from work carried out in the experimental psychology genre that emotion has a mediating effect on cognition. For instance, psychological arousal caused by a heightened emotional state aids the construction of memories, so that those memories are given an enhanced value and are more easily recalled at a later date (author, 2010; Bromm \& Desmedt, 1995; Nisbett \& Ross, 1980). The theoretical frame of the current study will draw specifically on mechanisms of attention, principally how the more emotionally-loaded a situation is, the more attention is afforded to that situation (Lang \& Davis, 2006).

Experiments involving the presentation of images of different species to human participants have shown that they automatically give more attention to fear-relevant animals (e.g. lions, spiders, snakes) than fear-neutral species (e.g. flowers, mushrooms, antelopes) (Öhman, Flykt, \& Esteves, 2001; Penkunas \& Coss, 2013). It has been argued that these mechanisms are linked to evolutionary processes that helped protect distant ancestors from carnivorous animals that were predators of humans (Öhman et al., 2001), or were competitors for a common prey/carrion. A natural fear of predators remains within children living in contemporary urban societies (Prokop \& Fančovičová, 2010); three year-olds have also demonstrated this attentional bias (LoBue, 2010). Yorzinski, Penkunas, Platt, and Coss (2014) showed that people can quickly detect images of dangerous animals and maintain their visual attention on those images, arguing that brains are pre-wired to focus on the possibility of predation.

In addition to having a disproportionate attentional bias towards predators, people generally consider carnivores to be more interesting animals than herbivores. For example, one of the most well-known and popular dinosaurs is the carnivorous Tyrannosaurus rex (Currie, 
Hurum, \& Sabath, 2003), and when children have been asked to spontaneously name any animal, carnivores such as tigers and lions frequently top the list (e.g. author, 2015; Chen \& Ku, 1998). Considering a single carnivore/herbivore pairing, Prokop and Kubiatko (2008) found that children were more interested in watching wolves rather than rabbits in natural history TV programmes. There is evidence to suggest that these preferences can be culturespecific. Prokop, Usak, and Erdogan's (2011) study uncovered more of an interest in, but also fear of grey wolves by primary-aged children in a country where wild wolves were common (Slovakia) compared with children from a community where wolves are much rarer (Turkey). Fears were diminished in children who had previously taken part in nature walks or had watched natural history films. There is however, contrary evidence that implies previous experiences play little part to the extent to which individuals are attentive to and remember information about carnivores that are dangerous to humans. Using primary-aged samples, Barrett and Broesch (2012) compared city-dwelling children from the US with Ecuadorian children living in the Amazonian rain forest by testing their abilities to remember facts about dangerous carnivores such as the Komodo dragon and the serval. Both groups performed equally well, preferentially recalling danger information and immediately forgetting dangerneutral facts about animal names and diet. One might have expected the Ecuadorians, who live with a real danger of deadly predators, to perform better. These data suggest that more innate, thus inheritable, mechanisms are at play that promote prepared social learning about dangerous aspects of the environment. This links with theories of adaptive memory (e.g. Nairne, Thompson, \& Pandeirada, 2007), which propose that modern humans have retained vestigial abilities to better remember information that was important to the survival of Paleolithic (and possibly earlier) ancestors. When asked to suggest animals that might live in a forest, first graders named more carnivores than herbivores (though some of these were 
inappropriate, e.g. sharks); in fact, there was a general attraction towards predators displayed by the children (Strommen, 1995).

Cain and Bohrer (1997) made the link between preschool children's fascination with violent predator/prey scenes from the film Jurassic Park and their views as to whether the violence was fantasy or real. Other researchers have commented that fantasy violence is used as a powerful device for grabbing children's attention in animated cartoons (Middle \& Vanterpool, 1999) and video games (Ferguson \& Olson, 2013). The Horrible Histories book series includes fantasy violence and distasteful stories that appeal to children and have helped make the author Terry Deary the bestselling history writer in the UK (Beck, 2012).

As will be discussed subsequently in the article, human adaptations based on natural cognitive predilections for predators and carnivores, and a liking for fantasy violence can help explain the different ways in which learners reason about food chains, as reported by both previous research and in the current study. It will also be discussed how attentional theory could be used as a basis for generating pedagogies that would assist children in constructing scientifically appropriate models of food chains. To operationalise the study, two research questions were formulated:

1. To what extent can preschool children demonstrate competence in understanding key concepts that are precursors for interpreting a three-step food chain?

2. Are preschool children capable of understanding the effects of changing populations on other species within a three-step food chain?

\section{Methodology}




\section{Participants and Setting}

A stratified sample of children aged 3, 4 and 5 years was accrued on an opportunity basis from five different privately-run nursery settings located in the south east of England. Each of the three age groups comprised of 25 children which provided a total sample number of 75 .

\section{Method}

The method was based on a procedure that had been used by the author during the course of a previous study with preschool children, deriving from a common approach in developmental psychology (author, 2015). This approach assumes that although preschoolers have thoughts and opinions that lie within the scientific realm (e.g. Ergazaki \& Andriotou, 2010), and are capable of scientific reasoning (e.g. Feist, 2008), it is difficult for researchers to completely determine these by means a standard interview. Many preschoolers are disadvantaged when they attempt to verbalise their ideas in speech due to developing literacy capabilities. An effective way to access their scientific thinking is indirectly, by making inferences about their beliefs and concepts from binary choices that the children make during interview (e.g. Jipson \& Gelman, 2007). Therefore, the current method consisted of presenting scenarios where children had to make a binary decision about the outcome (for example, an animal being 'happy' or 'sad'), and were then given an opportunity to explain that decision in their own words. As was the case with the author's previous study in 2015, the current research utilised plastic models of species as stimuli instead of drawings, because during piloting some children had quickly lost interested in the latter. Indeed, Prokop, Prokop, Tunnicliffe, and Diran (2007) found that 3D models of animals elicited better cognitive responses than 2D drawings. 
Children were interviewed singly by two researchers (the author and a research assistant) in either a private room or a quiet corner of the classroom; interviews typically lasted 10-15 minutes. The interviews were structured, with one of the researchers reading questions from a script while the second researcher wrote down children's spoken responses ad verbatim. To help present each child with as similar an experience as possible, additional probes were avoided, and were rarely used. Prior to main data collection the method had been piloted at a nursery that was not included in the final sample.

The interview consisted of two distinct parts. Part one focused on RQ1 and explored children's grasp of basic concepts that were precursors for comprehending three-step food chains. These were specifically: understandings of carnivorous/herbivorous behaviour; consumer/producer trophic levels; predator/prey relationships; and the ability to recall threestep food chains. The researchers used plastic models of species in order to illustrate these different scenarios, asking a predetermined series of questions that required children to make binary choices and explain their decisions. For example, for task $1 \mathrm{~d}$, concepts of predator/prey relationships were elicited by 'walking' models of a zebra and a lion towards each other on the table, then asking the child, 'who chases who?' Five food chains from different ecosystems were utilised in order to assess children's understandings in a variety of contexts, and with each food chain the children had to undertake seven tasks, each of which related to one of the above scenarios. The results and discussion section gives full details of the tasks, including the precise wording used by the researchers. The five ecosystems were: tropical rainforest (leaf $\rightarrow$ deer $\rightarrow$ tiger); African savannah (grass $\rightarrow$ zebra $\rightarrow$ lion); ocean (seaweed $\rightarrow$ angelfish $\rightarrow$ shark); pond and environs (leaf $\rightarrow$ caterpillar $\rightarrow$ frog); and temperate woodlands (grass $\rightarrow$ rabbit $\rightarrow$ fox). The particular food chain for each ecosystem 
was chosen because it was typical of those used in KS1 or KS2 teaching. An additional prerequisite to using these food chains was that the species therein would be familiar to the youngest children in the sample (3 years).

RQ2 enquired whether preschool children were capable of understanding the effects of changing populations on other species within a three-step food chain. To this end, part two of the interview used a single food chain - temperate woodlands (grass $\rightarrow$ rabbit $\rightarrow$ fox). This food chain was chosen because it has been one of the most common exemplars used in English school science, being prevalent in textbooks and teaching materials. Part two comprised of eight tasks that focused on aspects of changing populations within the food chain with respect to different ecological situations; these were: abundance of food; starvation; over-predation; and under-predation. As with part one, the tasks involved presenting these scenarios using plastic models and asking structured questions that required a binary answer followed by a verbal explanation. For example, for task $2 \mathrm{~d}$, models of grass, three rabbits and a fox were placed in front of the child who was then asked if the rabbits were to go on a long journey away from the wood, would the fox be happy or sad. The results and discussion section summarises precise wording of the questions and task procedure.

Given the young age of the children much attention was afforded to ethical considerations, with the author's faculty ethics committee approving the study prior to data collection. For instance, interview questions focusing on the death or starvation of animals were presented in such a way that the scenario was not alarming for the children. Informed consent was obtained from the managers of the early years settings, the children's parents, and the children themselves. 


\section{Analysis}

Analysis was driven by the two research questions in the sense that it was important to determine whether or not children had been competent in grasping principles that are precursors for understanding three-step food chains. It was also vital to look for differences in these competencies between the ages of 3-5 years. Both of these aspects helped create a learning progression for food chain competencies, which forms the essence of the findings (table 10, which will be discussed in the concluding section of the article).

In order to do this, analysis involved collating the raw data and producing tables of frequency counts for each task for each of the three age groups (tables 1-9). For the binary choice questions the analysis was comparatively simple; as the tables show, data comprised of counts of the numbers of children who had chosen either one of two animals, or said that an animal was happy or sad. Where children had given verbal responses, which were typically reasons for their binary choices, data were coded into qualitative categories using principles of conventional content analysis. This enabled the conversion of qualitative data into quantitative form so that statistical operations could be later applied. The qualitatively-coded categories created were not pre-determined but emerged from the data as analysis progressed (Miles \& Hubermann, 1994).

For each task, the first phase of qualitative coding involved the generation of a number of categories based on the responses children had given. Responses nearly always consisted of a single word or a brief sentence, which aided categorisation. For example, when children were asked during task $2 \mathrm{~d}$ why the fox was sad that all the rabbits had left the wood, the first phase of analysis generated nine categories of responses, including the fox was sad because it likes to eat rabbits, there are no rabbits left, the fox is lonely, or there is no more food to eat. The 
second phase of analysis involved data reduction where categories were collapsed into scientifically correct and incorrect sets, which is the form that is presented in the tables. This permitted subsequent statistical determination of whether an age group had been competent in a particular task (see below). Qualitative responses had been coded into categories first by the author and then independently by a second researcher. The inter-relater reliability coefficient was $92.7 \%$, which is acceptable.

Once counts had been determined, in order to address the research questions statistical operations were undertaken in order to test associations between the three different age groups and formulate a learning progression that gave details of how children's thinking changed with age. Also, competence in a task was assessed according to whether an age group had been successful at a level statistically greater than chance (50:50). Given the binary nature of much of the data, the operations applied were simple and complex chi square. Confidence limits for statistical significance were set at $95 \%$; probability values are indicated in the tables as follows: $* \mathrm{p}<0.05 ; * * \mathrm{p}<0.01 ; * * * \mathrm{p}<0.001 ; * * * * \mathrm{p}<0.0001$.

As mentioned, statistical tests determined whether there were significant differences between ages with a view to claiming whether or not there was evidence of typical learning progressions between the ages of three to five years, and if children were competent in a particular task. In order to contribute to the robustness of the study, statistically significant differences were used as a basis for claims made in the subsequent sections of the article. Therefore, if the difference was merely numerical (one number was bigger than another) then no claim was possible. All claims made in the following sections are based on statistically significant differences unless stated otherwise, and all statistical values can be found on the frequency tables. When a claim is made that is not recorded in the tables then the statistical 
value is given alongside the claim in the main text. For brevity, each year group is referred to thusly: three year-olds, 3s; four year-olds, 4s; and five year-olds, 5s. All values in the frequency tables represent numbers of children, not percentages or proportions (although percentages have been commonly cited in the main text).

\section{Results and discussion}

\section{Part one: Basic food chain concepts}

\section{la Identifying animals}

As a prelude to the subsequent tasks, the interview began with the researcher presenting plastic models of the herbivore and carnivore from each particular food chain and asking the child to name the animals. If the child did not know or gave an incorrect response, the researcher then provided the name. Children were nearly always able to correctly identify the models presented to them, showing that they were familiar organisms.

$1 b$ Determining herbivorous and carnivorous behaviour - free choice

Insert tables 1 and 2

Key concept: Identifying trophic levels in a food chain - primary and secondary consumers (herbivores and carnivores).

After the herbivore and carnivore models had been introduced, children were asked to suggest a food that each animal might eat: table 1 shows typical responses, while table 2 
records frequencies of responses. The examples that children gave were nearly all foods that each animal might encounter in the wild, e.g. the shark eats fish, or the caterpillar eats leaves. The foods were categorised into either plant or animal matter, and then used to determine whether children had nominated species as herbivorous or carnivorous. When all ages and food chains were considered collectively, substantial numbers of children performed well and could correctly allocate carnivorous $(50 \%)$ or herbivorous (43\%) behaviour to species. However, $42 \%$ of the sample either could not think of a food or gave an uncodeable response, e.g. the tiger eats 'dust from the zoo' (Frank, 5 y/o). Statistically, carnivorous and herbivorous behaviour were recognised equally well. In Gallegos et al.'s (1994) study, their older, primary-aged sample was more successful with $90 \%$ showing accuracy in recognising whether animals were carnivores or herbivores. In the current study, a small number of responses were anthropocentric in that they involved human action, e.g. the angelfish eats bread, chips, or fish food. Strommen (1995) similarly found that $1^{\text {st }}$ graders were largely accurate when naming foods that forest dwellers might eat, though a few were anthropocentric, e.g. a bear eats potato chips. Interestingly, seven children in the current sample said that the angelfish ate water, possibly linked to memories of a fish taking in water through its mouth as it maintains a constant flow over its gills.

There was an increase in performance between 3-5 years with recognising carnivorous behaviour, meaning that the $5 \mathrm{y} / \mathrm{o}$ had correctly identified an appropriate food for the carnivores better than the 3 and 4 y/o. The tiger and lion had proved tricky for the $3 \mathrm{~s}$ and $4 \mathrm{~s}$, many of whom attributed herbivorous behaviour to these species, whilst also stating that the herbivores in the same food chains (deer and zebra) also ate plants. However, there were no age differences when the herbivores were considered, therefore the $5 \mathrm{~s}$ were identifying appropriate foods for animals such as the zebra and caterpillar with the same accuracy as the 
3s and $4 \mathrm{~s}$. It may be the case that with this particular type of task, a preferential attentional bias towards predators begins to become apparent at around 5 years. This could make the older children more motivated to learn and read independently about carnivores compared to herbivores, and so were more aware of their feeding behaviour. Since there was no corresponding bias towards herbivores, knowledge remained largely static between 3-5 years.

1c Determining herbivorous behaviour - forced choice

Insert table 3

Key concept: Identifying trophic levels in a food chain - primary consumer (herbivore).

This task involved determining whether the child knew which of the two models represented the herbivore. The herbivore and carnivore models from each food chain in turn (e.g. deer and tiger, respectively) were placed on the table together and the plant model was introduced (e.g. leaf), with the child being asked, The [plant] is the favourite food of one of these animals - do you know which one? If the child said that both animals like to eat the plant, they were asked, Who likes the [plant] the most? Therefore, the child had to make a forced choice even if they believed both animals ate the plant; in effect, they had to judge which animal was the 'most herbivorous'.

Overall, a large majority of children were correct in determining herbivorous behaviour when they had to make a forced choice $(83 \%)$; for instance they knew that the deer, and not the tiger ate the leaf. When all food chains were considered together there was an increase in performance with age (table 3). When responding to this question, more children could successfully identify herbivorous behaviour compared with the preceding free choice task $1 \mathrm{~b}$ 
(83\% vs. $68 \% ; \mathrm{p}<0.0001)$. For instance, although there was still a tendency for some of the 3 s to think the tiger and lion as herbivorous, numerically the difference was less than with the preceding $1 \mathrm{~b}$. This improvement could be in part due to attentional bias towards carnivores by the older children who eliminated the carnivore when considering the binary choice because they knew it does not eat plants, rather than possessing precise knowledge about the herbivore's eating behaviour. Alternately, the 5s might have accessed a carnivore or herbivore mental prototype when making the categorical choice between the two animals, choosing the animal that most resembles their prototype. The transition boundary for agerelated change was for largely at 4-5 yrs, though there was smaller step at 3-4 yrs.

1d Establishing predator and prey roles - forced choice

Insert table 4

Key concept: Establishing ecological roles within a food chain - identify predator and prey.

The plant was taken away and ideas about which animal was the predator and which was the prey were explored by asking, Both animals are walking in the [ecosystem], then they suddenly meet - who chases who? An overwhelming majority of children could correctly identify the carnivore as being the chaser (92\%); for example, the tiger chases the deer, and not vice versa. There was an increase in performance with age, which like the preceding two tasks could be explained by a preferred attentional bias towards predators with the older children (table 4). These data tentatively infer that the choice of chasing animal indicates which the child thinks was a predator and which was its prey. When children gave reasons for the chase, or what happens after the chase (tasks 1e and 1f below), this confirmed predation since a feeding relationship was specifically declared. 
le The reasons why the predator chases the prey

Insert table 5

Key concept: Establishing ecological roles within a food chain - consequences of predation.

After determining the chaser the child was asked, Why does the [predator] chase the [prey]? Of children who offered a response, the most common reasons for chasing were feeding related (65\%), e.g. 'the tiger wants to eat deer for his dinner' (Amun, 5 y/o). The second most common was that because the prey species was frightened (11\%). Other reasons included the predator animal likes to chase, is strong, or is in the same vicinity as the prey. In a scientific sense the reason for predation is the predator utilising the prey as a food source, and within this feeding category there were increases in performance with age, with the 3 s performing relatively poorly (table 5). Again, this can be related to differences in attentional bias. Note that only responses that directly stated a feeding relationship were included in the 'correct' counts, therefore responses such as the predator will fight the prey, were not judged to be examples of predation. It may be these children know that a predator chases, but have not made the feeding connection.

If Events after the predator catches the prey

Insert table 6

Key concept: Establishing ecological roles within a food chain - consequences of predation. 
The children were then asked, What is the [predator] going to do to the [prey] when the [prey] is caught? For children who offered a response to this question a majority gave scientifically valid feeding-related consequences of being caught by the predator (77\%), e.g. "[the angelfish] goes in the shark's tummy" (Anna, 4 y/o). Other comments included the prey will be sad, scared, or will hide (table 6). As was the case with task 1e, because only feeding related responses were accepted as being scientific reasons for predation, answers such as the prey will be injured were not counted towards the eating category. There was an overall increase in performance between 3 and 5 years. There were however, more eating-related responses with this question than with the previous task 1e that asked the reason for the chase ( 215 vs. $135 ; \mathrm{p}<0.01)$. Children may only have realised that the predator is chasing the prey for food once it is caught, which brings home the act of predation in a more immediate, dramatic way. It was noticed during data collection that many children appeared to revel in the idea of the predator catching the prey, with some physically bashing the two models together, or speaking in an aggressive tone, statements such as 'the deer will die!' This could be considered a form of fantasy violence where the child has imagined a scenario involving the demise of the prey that they clearly found enjoyable.

$1 g$ Accurate recall of food chain

\section{Insert table 7}

Key concepts: Identifying trophic levels; establishing ecological roles.

Finally, to see if the food chain could be recalled correctly, with all three models in full view children were asked, Who likes eating the [plant]? Who likes eating the [herbivore]? The researcher placed the models in the positions stated by the child, and added two small card 
arrows between the organisms to form a visual representation of a three-step food chain. Most children could accurately reproduce the sequence of species within the food chains that they had previously constructed (82\%). There was an overall progression with age with each of the individual food chains (table 7).

\section{Part two: Effects of changing populations}

The temperate forest food chain (grass $\rightarrow$ rabbit $\rightarrow$ fox) was the sole focus for this part of the interview and the relevant plastic models were arranged in front of the child at the start of each task in correct trophic level order, complete with arrows, as they would appear in a standard diagrammatic three-step food chain .

Insert tables 8 and 9

\section{2 a Plant population increases}

Key concept: Changes in one population affect another species up the trophic levels abundance of producer scenario.

More grass was added to the grass already there and the child was asked, Lots more grass grows on the ground - is the rabbit happy or sad? Why? A majority of children (83\%) said the rabbit will be happy there is more grass (table 8). In this context, 'happy' was categorised as a scientifically correct response since an increase in the abundance of a food source enhances a species' probability of survival, and there is a greater chance of population increase since more offspring will be able to be fed. For those who were able to give a reason why the rabbit will be happy the largest category numerically was because 'rabbit eats grass' (52\%), which again was 
scientifically acceptable since children had made a link between the two species in the form of a feeding relationship (table 8). David (5 y/o) explained that the rabbit was happy because "more rabbits might like to eat [the grass]", implying that rabbits share and have empathy with other members of their species. Therefore, for about half of the children, plant blindness was not apparent, as might be expected considering previous studies (e.g. Hogan, 2000). Responses classified as non-scientific included the rabbit likes grass, or more grass means the rabbit will be able to escape from the fox. There were no statistical differences with respect to age with all year groups performing equally well.

\section{$2 b$ Plant population decreases}

Key concept: Changes in one population affect another species up the trophic levels - starvation of herbivore scenario.

A second rabbit was introduced and all grass removed from the table. A naughty rabbit comes and eats all the grass, then goes away. Is the first rabbit going to be happy or sad? Why? Nearly all of the children (96\%) said the rabbit would be sad that the grass was gone (table 8), which was the scientific response, and there were no age differences. However, only $29 \%$ were able to offer a reason that could be also classified as scientific - because the rabbit can no longer eat grass. The most common response was that the rabbit was sad simply because the grass was gone (62\%), with children failing to verbalise a feeding relationship.

This question was followed by, What will happen to the first rabbit now there is no grass to eat? Almost a third of children (29\%) gave a reason that was categorised as scientific, linking consequences to a reduction in food supply to detrimental effects on the health of the rabbit, 
i.e. it will not grow, become unhealthy, or die (table 8). The question also explored children's ideas of intra-species competition and Angela ( $4 \mathrm{y} / \mathrm{o}$ ) was one of the few who appeared to understand (in a simple way) that wild animals compete for food, 'he will chase the naughty rabbit away.' A handful of children expressed erroneous ideas of extra-chain reasoning in the form of a varied diet outside of the food chain, for instance stating that the rabbit will move away and find more grass. Frank ( 4 y/o) was willing to consider alternative food sources from an anthropocentric perspective: "he will go to people's houses and eat grass."

In this task more children understood the effects of population disappearance than population abundance in the scenario offered by the preceding task $2 \mathrm{a}(\mathrm{p}<0.05)$. There are similarities here with the later tasks $2 \mathrm{c}$ and $2 \mathrm{~d}$ (below) because children could be conceptualising the rabbit feeding off grass as a weak variant of predation. Research with high school pupils has uncovered the misconception that if a species is higher in a food chain, it is a predator of all those below it (Barman, Griffiths, \& Okebukola, 1995; Griffiths \& Grant, 1985). In fact, some ecologists argue that herbivores can be viewed as predators of plants (Davic, 2002). The starvation scenario was better understood than the abundance scenario probably because starvation is a starker example of the consequences of (failed) 'pseudo-predation'. As with task $2 \mathrm{a}$, children were not affected by plant blindness.

\section{2c Prey population increases}

Key concept: Changes in one population affect another species up the trophic levels - prey abundance scenario. 
Two more rabbits were added making a total of three in the food chain. Another two rabbits come into the forest, is the fox happy or sad? Why? Just over half of the children (57\%) said the fox would be happy, which was the scientific response (table 8). There was an age-related increase in performance, with about twice as many $5 \mathrm{~s}$ opting for 'happy' than $4 \mathrm{~s}$ or $3 \mathrm{~s}$. A few children who had suggested the fox would be sad projected anthropomorphic feelings of loneliness onto the fox, e.g. "[the fox's] mummy and dad are not there but the [rabbit's] mummy and daddy are" (Enalu, 4 y/o). For children who said the fox would be happy the most common answer by far was eating-related (34 eating vs. 4 others), with no differences between the ages (table 8). If one considers the attentional bias hypothesis, then the older children were conceptualising predation effects better than their younger counterparts because they have more of a preference for learning about predators/carnivores. Conversely, there was no clear age progression with the preceding tasks $2 \mathrm{a}$ and $2 \mathrm{~b}$ because knowledge of the herbivore/producer relationship did not change with age. In addition, with this task fewer children were correct compared with those who during task 2 a stated that a rabbit would be happy if the grass became abundant $(\mathrm{p}<0.01)$. This was an interesting comparison because one might expect plant blindness to have played more of a role in task $2 \mathrm{~b}$. This anomaly could be due to the $3 \mathrm{~s}$ and $4 \mathrm{~s}$ in the current task $2 \mathrm{c}$ understanding less about carnivores and more about herbivores.

\section{2d Prey population decreases}

Key concept: Changes in one population affect another species up the trophic levels - predator starvation scenario.

All the rabbits were removed. The rabbits have gone far, far away. Will the fox be happy or sad? Why? A substantial majority of children said that the fox would be sad (92\%), which is 
the scientific response, and there were no age differences (table 8). Therefore, the stark consequences of predator starvation were well understood by even some of the younger children in the sample, despite their relatively poor performance in other tasks that tested an awareness of predation effects. The most common reason given for the fox being sad was because its food source is disappearing (50\%), which is a scientific response, and the $4 \mathrm{~s}$ performed better than the $3 \mathrm{~s}$ in this regard (table 8 ).

The next question, What will happen to the fox now there are no rabbits to eat?, confirmed understandings of the consequences of removing a food source, with $47 \%$ stating that the fox suffers from a lack of food, or will die, with more $5 \mathrm{~s}$ than $3 \mathrm{~s} / 4 \mathrm{~s}$ citing death as a reason (table 8). Therefore, a greater appreciation of the effect of predator starvation was clearly experienced by the 5s. Seven non-scientific responses showed extra-chain reasoning of a varied diet outside the food chain (Smith, 2004), stating the fox will move away to new area (5 children) or find more prey (2), while others skipped trophic levels by stating that the fox will now eat the grass (7). Andrew (5 y/o) expressed extra-chain reasoning with implications of infinite resources, '[the fox] will die. Foxes eats chickens, won't die if he finds chickens.'

\section{2e Predator population increases}

Key concept: Changes in one population affect another species down the trophic levels - overpredation scenario.

Two more foxes were added. More foxes come into the forest, is the rabbit happy or sad? Why? The task tested erroneous static or semi-static models where effects down the trophic levels cannot exist (e.g. Arkwright, 2014). Nearly all of the children (96\%) correctly said that 
the rabbit would be sad if two more foxes were added to the food chain (table 9). The most common reasons were that foxes eat rabbits $(61 \%)$, which was scientifically correct, or chase rabbits (9\%), which was categorised as incorrect because there was no explicit mention of feeding, therefore predation could not be assumed (table 9). A few children appeared to have the idea that the three foxes would be able to gang-up on the rabbit or hunt as a pack, "they are going to go together and eat the rabbit" (Harry, 5 y/o). There were more $5 \mathrm{~s}$ than $3 \mathrm{~s}$ who said rabbits were sad because foxes either eat or chase them, and there were no further age differences. Attentional bias towards predation would explain why the 5 s were able to give more correct verbal explanations, although the negative effect on prey of more predators was the favoured option for all ages. As with task 1e, some children play-acted scenes of fantasy violence with the models, which gave further clues to their good comprehension of this scenario - despite this effect going down the trophic levels it was generally well understood. The high frequency of correct responses indicates that static or semi-static models were not apparent.

\section{$2 f$ Predator population decreases}

Key concept: Changes in one population affect another species down the trophic levels - underpredation scenario.

All the foxes were removed. The foxes go on a long journey away from the forest. Is the rabbit happy or sad? Why? When all the foxes disappeared from the food chain a majority of children (71\%) thought the rabbits would be happy, which is the scientific response (table 9). More 5s chose happy than $3 \mathrm{~s}$ or $4 \mathrm{~s}$. For children who chose happy the most common reasons were that the rabbit will not be eaten/die/is safe (32\%) which are scientifically acceptable (table 9). 
Overall, the scientifically correct frequencies were less than with the preceding over-predation task $2 \mathrm{e}(\mathrm{p}<0.0001)$ probably because for the children, the survival from predation outcome is not as stark as the consequences of predation itself. The $5 \mathrm{~s}$, however, performed the same as they did during the over-predation task $2 \mathrm{e}$, which indicates a wider, more complete appreciation of predation.

\section{$2 g$ Plant population decreases (effect on predator)}

Key concept: Changes in one population affect another species up the trophic levels - indirect effects.

A second rabbit was introduced and all the grass removed from the table. The naughty rabbit comes back and eats all the grass again. Is the fox happy or sad? Why?' This was followed by, What will happen to the fox now there is no grass? This task addressed the key concept of interpreting an indirect effect (between non-adjacent populations), and whether children are prepared to skip trophic levels by erroneously applying a direct effect between the fox and the grass. The scientific response would involve two steps of reasoning - the lack of grass caused the rabbit population to decrease due to starvation, which would in turn decrease the fox population.

Responses were fairly evenly divided between the fox being happy or sad, with slightly fewer children stating the scientifically correct 'sad' (45\%), and there were more $3 \mathrm{~s}$ and $4 \mathrm{~s}$, than $5 \mathrm{~s}$, who chose sad (table 9). Of the 34 children who chose that the fox would be sad, the most common response was that it was sad simply because the naughty rabbit has eaten the grass, or that the grass is now gone, without any further explanation (68\%). None of the reasons 
could be classified as scientific, therefore the children held a semi-static model. Gotwals and Songer (2010, p. 273) found similar results with their primary-aged sample, ‘... students were not able to see how an increase in the grain (a producer) could influence the snakes that are two trophic levels above the grain.'

\section{$2 h$ Predator/plant relationship}

Key concept: Changes in one population affect another species up the trophic levels erroneously skipping trophic levels.

Children were asked, The fox eats the rabbit, but can it eat the grass as well? This task tested in a straightforward way whether children are prepared to skip trophic levels in the food chain and assume an erroneous, direct feeding relationship between the predator and the producer. Just under half of the sample $(45 \%)$ stated that the fox cannot eat the grass, which is the scientific response, with performance increasing with age (table 9). The fact that a slim majority $(51 \%)$ were willing to skip trophic levels in the food chain and have the fox eating the grass as well as the rabbits concurs with the findings from previous studies with older students (e.g. Griffiths \& Grant, 1985), and could be an example of predation bias creating erroneous reasoning; in this case, a predator is able to eat all species below it in the food chain.

Insert table 10

\section{Conclusions and implications for practitioners}

The first research question enquired about the extent to which preschool children can demonstrate competence in key concepts that act as precursors for understanding three-step 
food chains. 'Competence' was defined as when children could offer scientifically correct responses at a level statistically greater than chance; table 10 presents these competencies as a learning progression from 3-5 years. Although the part 2 tasks looked at effects on single animals and not whole populations, these effects are a necessary first step for understanding population changes in food chains. The simpler key concepts reflected in these competencies appear in the English KS1 National Curriculum, while the quantitative concepts involving the effects of changing populations (second research question) are typically taught in KS2. The learning progression in table 10 suggests a sequence that these ideas should ideally be taught to children because they are in the order that they naturally emerge as young minds develop (author, 2016). Despite displaying some classic misconceptions, the preschool children were able to understand many of these ideas, suggesting that feeding relationships and food chains could be introduced to them in a simple way from 3 years upwards. In fact, many of the $3 \mathrm{~s}$ were capable of grasping quantitative aspects, for example reducing an animal's food source results in starvation and death, and so potentially the basics of food chains as dynamic systems could be presented at nursery level. Food chain knowledge is essential for understanding wider ecological issues and if these matters can be introduced to preschoolers then it would enable future scientific literacy, and there could be more of a probability of children developing into adults who are concerned environmentalists (Slarp, 2014). Furthermore, it is a good idea to teach young children appropriate scientific ideas before misconceptions can become 'hard wired' in later life (Segal \& Cosgrove, 1993, p. 276).

Humans are a problem-seeking species, being sensitive to aspects of their surroundings that could potentially have negative consequences. The phenomenon of inheritable, psychological self-defence mechanisms is well-established, appearing in Carl Sagan's (1977) Pulitzer Prizewinning book The Dragons of Eden, and can be traced to earlier research in the experimental 
psychology genre (e.g. Seligman, 1970). However, Sagan's hypothesised version of a form of race memory, where an innate fear of reptiles (and perpetuations of dragon myths) might have their roots in aeons-old conflicts between early mammals and dinosaurs, does not completely concur with contemporary theory. Modern psychologists such as Öhman assume that people possess the adaptation of affording preferential attention to predators such as snakes and lions because it has been advantageous to, and subsequently inherited from, their early forebears (Barrett \& Broesch, 2012; Yorzinski et al., 2014). Over history, natural selection processes have ensured that these tendencies are still latent in people today who are in no real danger of predation, and have even been demonstrated in 8 month-old infants, which helps to discount prior learning as the sole factor (Yorzinski et al., 2014). The following sequence of cognitive events can account, to some degree, for learners' reasoning with respect to food chains:

\begin{tabular}{|c|c|c|c|c|}
\hline $\begin{array}{l}\text { Evolutionary } \\
\text { predator } \\
\text { avoidance } \\
\text { mechanisms }\end{array}$ & $?$ & $\begin{array}{l}\text { Enhanced } \\
\text { attention on } \\
\text { predators }\end{array}$ & $?$ & $\begin{array}{l}\text { Disproportionate } \\
\text { focus on the } \\
\text { effects of } \\
\text { predation }\end{array}$ \\
\hline
\end{tabular}

Natural cognitive biases towards predators help explain erroneous food chain reasoning that has been established by previous research; for instance, thinking that a predator hunts all species below itself in the food chain (Griffiths \& Grant, 1985). As discussed in some detail in the previous sections, preferential predation bias was offered as a warrant for much of the current data, particularly the effect of age on performance. Overall, the 5 s appeared to be the most susceptible to predation bias, which nearly always acted as a positive influence helping them to show competence in the tasks, and also give scientifically-valid reasons for their binary choices. A greater interest by the $5 \mathrm{~s}$ in carnivorous rather than herbivorous diets, and 
predator/prey rather than herbivore/producer relationships, would imply that they had previously learned more information about carnivores and predators than their younger counterparts, and so could better explain when questioned aspects of predation such as the detrimental effects of prey disappearance. In contrast, knowledge of herbivore diets and herbivore/producer relationships did not change with age. As Leach et al. (1992) explain, children understand effects resulting in starvation scenarios better than abundance of food scenarios because starvation is a more stark consequence and so easier to imagine, and this trend was also apparent in the current data. In tandem with this, events up the trophic levels challenge learners to imagine how predators would be affected (or pseudo-predators such as herbivores eating plants), while those down the levels ask them to think about effects on prey. If learners preferentially focus on predators more than prey, this might help explain why previous research has found effects down the trophic levels to be more difficult to understand.

This tendency to better process the effect of changing populations up rather than down the trophic levels was not reflected completely in the current data since the older children could comprehend effects both up and down the trophic levels equally well. A majority of the 5s were able to see the effects of over- and under-predation on the prey species down the trophic levels (although the $3 \mathrm{~s}$ could not). This anomaly could be due to the way the tasks were presented to the children - perhaps using physical models provided more support to their understanding compared with the traditional paper and pencil tasks utilised by the three earlier studies that have commented on this trend (Demetriou et al., 2009; Gotwalls \& Songer, 2010; Leach et al., 1992). Particularly, the way in which the number of models were physically increased or decreased in the food chain likely acted as a visual aid to quantitative understanding. For these reasons, and although no pedagogy was formally tested, it is 
suggested that the tasks could be used as physical tools when teaching food chains to young children; especially, the construction of erroneous static models of food chains may be avoided.

Although not an explicit focus of the study, it was noted that some children exhibited behaviour that implied they were acting out scenes of fantasy violence during the predation scenarios. These feelings might have acted as a further boost to their natural interest in the predation act, or may have simply been a symptom of their heightened focus towards predation during the tasks. Cain and Boher (1997, p. 72) describe how nursery children's violent descriptions of events from Jurassic Park were eradicated after a calming programme of activities that used knowledge about dinosaurs in '...other, more constructive ways'. It could be conversely argued that some children's natural preferences for the gory and violent could be used as foci to help engagement and understanding, as is the rationale underpinning the Horrible Histories books. Using predation scenarios as a prelude to discussing how food chains work would be one way to do this. The current data show that predation bias was more apparent with the $5 \mathrm{~s}$, however, younger children could be encouraged to accelerate their natural progression towards an affinity to predation, which would increase their performance in food chain competency. At the opposite end of the scale, one potential issue with older children is allowing predation bias to excessively influence their reasoning resulting in misconceptions such as a top predator hunts all species below it in a food chain, ignoring herbivore/producer relationships causing plant blindness, or being less able to process events down the trophic levels.

A limitation of the study is that food webs, which are more holistic representations of feeding relationships in ecosystems, were not considered for reasons of complexity and potentially 
not being able to isolate individual concepts due to multiple feeding pathways. Further research could remedy this by investigating concepts governing preschoolers' comprehensions of four and five-step food chains, and then eventually moving onto food webs. Ergazaki and Andriotou (2010) note that when preschool children show erroneous extra-chain reasoning such as suggesting alterative food sources outside the food chain, this may indicate that given appropriate tasks they could be capable of understanding simple food webs. This represents a positive sign that practitioners could enhance preschoolers' ecological education to a far greater level than is currently the case.

\section{References}

Author (2010). Journal of Research in Science Teaching.

Author (2015). Journal of Research in Science Teaching.

Author (2016). Book.

Almeida, A., Vasconcelos, C. M., Strecht-Ribeiro, O., \& Torres, J. (2013). Non-

anthropocentric reasoning in children: Its incidence when they are confronted with ecological dilemmas. International Journal of Science Education, 35, 312-334.

Arkwright, A. B. (2014). Fourth and eighth grade students' conceptions of energy flow through ecosystems (unpublished $\mathrm{PhD}$ dissertation). University of Kentucky, Lexington, KY. 
Barman, C. R., Griffiths, A. K., \& Okebukola, P. A. (1995). High school students' concepts regarding food chains and food webs: A multinational study. International Journal of Science Education, 17, 775-782.

Barrett, H. C., \& Broesch, J. (2012). Prepared social learning about dangerous animals in children. Evolution and Human Behavior, 33, 499-508.

Beck, P. J. (2012). Presenting history: Past and present. London: Palgrave Macmillan.

Bromm, B., \& Desmedt, J. (1995). Pain and the brain: From nociception to cognition. New York, NY: Raven Press Ltd.

Cain, B., \& Bohrer, C. (1997). Battling Jurassic Park: From a fascination with violence toward constructive knowledge. Young Children, 52, 71-73.

Chen, S. H., \& Ku, C. H. (1998). Aboriginal children's alternative conceptions of animals and animal classification. Proceedings of the National Science Council (Part D), 8, 55-67.

Currie, P. J., Hurum, J. H., \& Sabath, K. (2003). Skull structure and evolution in tyrannosaurid dinosaurs. Acta Palaeontologica Polonica, 48, 227-234.

Davic, R. D. (2002). Herbivores as keystone predators. Conservation Ecology, 6, r8. Retrieved from http://www.consecol.org/vol6/iss2/resp8/ 
Demetriou, D., Korfiatis, K., \& Constantinou, C. (2009). A ‘bottom-up’ approach to food web construction. Journal of Biological Education, 43, 181-187.

Department for Education. (2013). Science programmes of study: KS 1 \& 2. London: Crown Copyright.

Eisen, Y., \& Stavy, R. (1992). Material cycles in nature: A new approach to teaching photosynthesis in junior high school. The American Biology Teacher, 54, 339-342.

Ergazaki, M., \& Andriotou, E. (2010). From 'forest fires' and 'hunting' to disturbing 'habitats' and 'food chains': Do young children come up with any ecological interpretations of human interventions within a forest? Research in Science Education, 40, 187-281.

Feist, G. J. (2008). The Psychology of Science and the Origins of the Scientific Mind. New Haven, CT: Yale University Press.

Ferguson, C. J., \& Olson, C. K. (2013). Friends, fun, frustration and fantasy: Child motivations for video game play. Motivation and Emotion, 37, 154-164.

Gallegos, L., Jerezano, M. E., \& Flores, F. (1994). Preconceptions and relations used by children in the construction of food chains. Journal of Research in Science Teaching, 31, $259-272$. 
Gotwals, A. W,. \& Songer, N. B. (2010). Reasoning up and down a food chain: Using an assessment framework to investigate students' middle knowledge, Science Education, 94, 259-281.

Griffiths, A. K., \& Grant, B. A. C. (1985). High school students' understanding of food webs: Identification of a learning hierarchy and related misconceptions. Journal of Research in Science Teaching, 22, 421-436.

Hmelo-Silver, C. E., Marathe, S., \& Liu, L. (2007). Fish swim, rocks sit, and lungs breathe: Expert-novice understanding of complex systems. Journal of the Learning Sciences, 16, 307331.

Hogan, K. (2000). Assessing students' system reasoning in ecology. Journal of Biological Education, 35, 22-28.

Hogan, K., \& Fisherkeller, J. (1996). Representing students' thinking about nutrient cycling in ecosystems: Bidimensional coding of a complex topic. Journal of Research in Science Teaching, 33, 941-970.

Jiménez-Tejada, M. P., Sánchez-Monsalve, C., \& González-García, F. (2013). How Spanish primary school students interpret the concepts of population and species. Journal of Biological Education, 47, 232-239.

Jipson, J. L., \& Gelman, S. A. (2007). Robots and Rodents: Children's inferences about living and non-living things. Child Development, 78, 1675-1688. 
Katsiavou, E., Liopeta, K., \& Zogza, V. (2000). The understanding of basic ecological concepts by preschoolers: Development of a teaching approach based on drama / role play about independence of organisms. Themes of Education, 1, 241-262.

Lang, P. J., \& Davis, M. (2006). Emotion, motivation, and the brain: Reflex foundations in animal and human research. Progress in Brain Research, 156, 3-29.

Leach, J., Driver, R., Scott, P., \& Wood-Robinson, C. (1992). Progression in conceptual understanding of ecological concepts by pupils aged 5-16. Centre for Studies in Science and Mathematics Education, University of Leeds.

LoBue, V. (2010). And along came a spider: An attentional bias for the detection of spiders in young children and adults. Journal of Experimental Child Psychology, 107, 59-66.

Manzanal, F. R., Barreiro, R. L. M., \& Jiménez, C. M. (1999). Relationship between ecology fieldwork and student attitudes towards environmental protection. Journal of Research in Science Teaching. 36, 430-453.

Middleton, Y., \& Vanterpool, S. M. (1999). TV cartoons: Do children think they are real? Reports Research/Technical Tests/Evaluation Instruments, 143, 1-15.

Miles, M. B. \& Huberman, A. M. (1994). Qualitative Data Analysis: An Expanded Sourcebook (2nd Edition). Thousand Oaks, CA: Sage Publications. 
Munson, B. H., (1994). Ecological misconceptions. Journal of Environmental Education, 25, $30-34$.

Nairne, J. S., Thompson S. R., \& Pandeirada, J. N. S. (2007). Adaptive memory: Survival processing enhances retention. Journal of Experimental Psychology: Learning, Memory and Cognition, 3, 263-273.

Nisbett, R., \& Ross, L. (1980). Human inference: Strategies and shortcomings of social judgement. Englewood Cliffs, NJ: Prentice Hall.

Öhman, A., Flykt, A., \& Esteves, F. (2001). Emotion drives attention: Detecting the snake in the grass. Journal of Experimental Psychology: General, 130, 466-478.

Öztürk, D. K. (2010). Preschool children's attitudes towards selected environmental issues (unpublished MSc dissertation). Middle East Technical University, Ankara.

Penkunas, M. J., \& Coss, R. G. (2013). Rapid detection of visually provocative animals by preschool children and adults. Journal of Experimental Child Psychology, 114, 522-536.

Prokop, P., Usak, M., \& Erdogan, M. (2011). Good predators in bad stories: Cross-cultural comparison of children's attitudes toward wolves. Journal of Baltic Science Education, 10, $229-242$.

Prokop, P., \& Fančovičová, J. (2010). Perceived body condition is associated with fear of a large carnivore predator in humans. Annales Zoologici Fennici, 47, 417-425. 
Prokop, P., \& Kubiatko, M. (2008). Bad wolf kills lovable rabbits: Children's attitudes toward predator and prey. Electronic Journal of Science Education, 12, 1-16.

Prokop, P., Prokop, M., Tunnicliffe, S. D., \& Diran, C. (2007). Children's ideas of animals' internal structures. Journal of Biological Education, 41, 62-67.

Sagan, C. (1977). The Dragons of Eden: Speculations on the Origin of Human Intelligence. New York, NY: Ballantine.

Sander, E., Jelemenska, P., \& Kattmann, U. (2006). Towards a better understanding of ecology. Journal of Biological Education, 40, 119-123.

Segal, G., \& Cosgrove, M. (1993). 'The sun is sleeping now': Early learning about light and shadows. Research in Science Education, 23, 276-285.

Seligman, M. (1970). On the generality of laws of learning. Psychological Review, 77, 406418.

Shepardson, D. P. (2002). Bugs, butterflies, and spiders: Children's understandings about insects. International Journal of Science Education, 24, 627-643.

Slarp, M. (2014). How ecoliterate is a five year-old? Investigating the effects of a teaching intervention on kindergarten children's understanding of ecological concepts (unpublished MSc dissertation). University of Sydney, New South Wales. 
Smith, A. (2001). Early childhood: A wonderful time for science learning. Australian Primary and Junior Journal, 17, 52-55.

Smith, S. M. (2004). A cross-age study of students' conceptual understanding of interdependency in seed dispersal, pollination, and food chains using a constructivist theoretical framework (unpublished $\mathrm{PhD}$ dissertation). North Carolina State University, Raleigh, NC.

Strommen, E. (1995). Lions and tigers and bears, oh my! Children's conceptions of forests and their inhabitants. Journal of Research in Science Teaching, 32, 683-698.

Suzuki, K., Yamaguchi, E., \& Hokayem, H. (2015). Learning progression for Japanese elementary students' reasoning about ecosystems. Procedia-Social and Behavioral Sciences, $167,79-84$

Taşkın, Ö., \& Şahin, B. (2008). The concept of environment in six year-old preschool children. Pamukkale Üniversitesi Ĕ̈itim Fakültesi Dergisi, 1, 1-14.

White, P. (2000). Naïve analysis of food web dynamics: A study of causal judgment about complex physical systems. Cognitive Science. 24, 605-650.

Yorzinski, J. L., Penkunas, M. J., Platt, M. L., \& Coss, R. G. (2014). Dangerous animals capture and maintain attention in humans. Evolutionary Psychology, 12, 147470491401200304 
Early understandings of simple food chains 